\title{
A faculdade de direito de São Paulo e a avaliação do sotaque paulistano
}

Victor Carreão*

UNICAMP

\author{
Recebido em: 08/04/2019 \\ Aceito em: 08/11/2019
}

\begin{abstract}
Resumo: A escolha de São Paulo para ser o lar da Faculdade de Direito foi contestada por conta do sotaque paulista(no), classificado, na época, como o dialeto "mais errado" do Brasil durante os debates da constituinte de 1823. Mais de um século depois, essa mesma variedade dialetal tem algumas de suas variantes de fala observadas em grandes telejornais. De forma a melhor entender essa trajetória, verificamos, em relatos de viajantes do início do século XIX e em gramáticas da época, o prestígio de diferentes traços linguísticos paulista(no)s e como se associavam às áreas urbanas da cidade.
\end{abstract}

Palavras-chave: Dialeto paulista. Gramatização. Avaliação sociolinguística.

\begin{abstract}
Choosing São Paulo to be home to the Faculty of Law was contested because of São Paulo's speech, classified, back then, as the "most incorrect" dialect in Brazil - during the debates of 1823's Constitution. More than a century later, this same dialectal variety has some of its variants of speech observed in major television programs. In order to understand this trajectory, it was observed, in travelers' diaries from the 19th century and in the grammars of the time, the prestige of different linguistic traits found in São Paulo and how they relate to urban areas of the city.
\end{abstract}

KEY-WORDS: Paulista dialect. Grammarization. Sociolinguistics evaluation.

Résumé: Le choix de São Paulo comme la Faculté de droit a été contesté à cause de l'accent de São Paulo, classé à l'époque comme le "plus mauvais" dialecte du Brésil - lors des débats constitutionnels de 1823. Un siècle plus tard, cette même variété dialectale a de ses variantes de discours observées dans les grands journaux télévisés. Pour mieux comprendre cette trajectoire, nous trouvons dans les récits de voyageurs du début du XIX siècle et dans les grammaires du temps, le prestige de différents traits linguistiques à São Paulo et la manière dont ils étaient associés aux ses zones urbaines.

Mots-clés: dialecte pauliste. Grammarisation. Évaluation sociolinguistique.

\section{Introdução}

Muitos estudos sociolinguísticos abordam a avaliação e percepção linguística dos indivíduos. Um deles é o de Labov (2008 [1972]) em que gravações de determinado falante são apresentadas a outros indivíduos e cabe a estes classificar o enunciador das gravações em categorias como "mais instruído" ou "menos instruído", "com maior 
tendência a brigas" ou "com menor tendência a brigas”, entre outras características de natureza socioeconômica ou de personalidade.

A produção e a percepção linguística também são objeto de estudo da Psicologia Social. Pesquisas envolvendo o teste conhecido como "matched guise" (LAMBERT et al, 1960), em que um falante é gravado ao ler determinada passagem textual em dois momentos, sendo cada um deles registrado de maneira diferente (seja em outra língua ou em outro dialeto, por exemplo). Essas gravações são apresentadas a diferentes indivíduos que devem classificar o falante das gravações - sem saber que seu enunciador é a mesma pessoa nos dois casos - em diferentes categorias sociais ou de personalidade. Trabalhos da área nos mostram que marcas linguísticas podem influenciar no julgamento que se tem de alguém por conta de sua variedade de fala.

Os estudos sobre percepção têm seu início na década de 1960, mas avaliações linguísticas são encontradas muitos anos antes desse tipo de pesquisa. Em particular, escolhemos um comentário realizado durante os debates da Constituinte de 1823 (na época do Brasil Império) como ponto de partida para este trabalho. Um dos pontos definidos pela Constituinte da época dizia respeito à instalação de uma faculdade de direito em solo brasileiro. Entre os argumentos dos deputados, há um que diz respeito à avaliação de uma variedade de língua: o dialeto paulista. A menção a este dialeto é retratada, por Toledo (2012, grifos nossos), em uma dessas discussões:

\footnotetext{
Raras vezes terá ficado registrado para a História documento tão revelador do que se pensava, na época, de São Paulo e dos paulistas, do que as atas da Constituinte relativas ao tema da criação de uma instituição de ensino superior no Brasil. A questão do sotaque paulista - ou paulistano - virou argumento recorrente. "É geralmente reconhecido que, assim como na província de Minas é mais apurado o dialeto, assim também na de São Paulo é onde o há menos correto", disse o deputado mineiro Lúcio Teixeira de Gouveia. "E ninguém ousará negar que esta circunstância também é atendível para a escolha do local onde se devem estabelecer academias" (TOLEDO, R. P. 2012, p. 226-227).
}

Alguns documentos trazem a nomenclatura "província de São Paulo", mas ressaltamos que, aqui, falamos da variedade de fala do estado de São Paulo (paulista). Após a formação da cidade de São Paulo, com a urbanização, é possível apontar uma variedade paulistana. Na citação anterior, há menção à fala paulista como "menos correta”. Matos (1955, p. 96), ainda sobre a questão da instalação da Faculdade de Direito em São Paulo, também faz menção à avaliação da variedade de fala paulista 
mostrando que aqueles que eram contra a escolha de São Paulo diziam que ali se “contrairia pronúncia mui desagradável”.

A importância de uma Faculdade de Direito era grande não apenas para o país, mas também para a região em que fosse instalada. Esperava-se que a faculdade projetasse a região para tempos de maior riqueza e crescimento intelectual e "um falar desagradável” ou "rústico" não deveria combinar com esse tipo de status. Matos (1955, p. 102) ressalta que São Paulo, após a instalação da faculdade, tornou-se "uma cidade procurada por jovens procedentes de todos os recantos do Brasil”.

Freyre (apud Matos, 1955, p. 102) ressalta que "São Paulo madrugou na paisagem não só brasileira mas sul-americana, como centro de uma civilidade menos urbana porém mais cívica que a irradiada das cidades-Côrtes". A instalação da Faculdade de Direito pode ser entendida como um marco da civilidade paulista. Como essa referência na história do estado se iniciou com debates sobre a língua, é interesse verificar como a variedade de fala de São Paulo mudou com o passar do tempo.

Pensando em avaliações negativas em relação a uma variedade de fala, um exemplo de estigma, no estado de São Paulo, é o caso da fala caipira. Ao estudar o “dialeto caipira” em regiões interioranas do estado de São Paulo, Amaral (1920) aponta características de um falar rústico que estaria com seus dias contados uma vez que a urbanização e a educação logo se irradiariam para o interior do estado. Para Robl (1985, p. 164) "o chamado 'dialeto caipira', ainda vegetando em alguns lugares interioranos e insulados, é um dos remanescentes do semicrioulo dos tupis e caboclos do BrasilColônia" (ROBL, 1985, p. 164). Matos (1995, p. 96) menciona que a variedade paulista teria "influência cabocla". Essas características ajudam a explicar o motivo que justificaria o comentário do deputado Lúcio Teixeira de Gouveia, nos debates da Constituinte de 1823, em relação ao dialeto paulistano ser "menos correto".

Essa avaliação sobre o dialeto paulistano é diferente nos dias de hoje. A variedade de língua empregada em grandes veículos de informação, como o Jornal Nacional, apresenta características - uma ou outra forma linguística - da fala paulistana atual:

Em função de um padrão Global de qualidade e de uma suposta maior compreensibilidade, Beuttenmüller [fonoaudióloga da emissora de TV Rede Globo, em 1974] criou o falar-padrão da Rede Globo: um falar que não pertence, de fato, a nenhuma cidade do Brasil. Poder-se-ia denominar o falar 
do Jornal Nacional, o falar da "Via Dutra", do eixo Rio-São Paulo. Ou seja, um falar cujas características estão compreendidas entre os falares das cidades Rio de Janeiro (padrão estabelecido) e São Paulo (ausência de "esses" sibilantes, chiados, e de "erres" guturais) (MENDES, 2006, pp. 21-22. Grifos nossos).

O registro feito pelo deputado sobre a variedade de São Paulo não faz menção a uma forma linguística em específico, mas aponta que os habitantes da província de São Paulo (termo utilizado nas gramáticas da época) apresentam uma variedade que destoaria do restante do país. Em um comparativo com tempos atuais, a variedade paulista é avaliada, em certos casos, positivamente. Um dos casos em que isso é observado é no trabalho de Ramos (1997, p. 105), em que dois questionários foram aplicados a 60 falantes de classe média, de 14 ou 15 anos e entre 25 e 40 anos, em cinco estados: Rio Grande do Sul, Santa Catarina, Minas Gerais, Rio de Janeiro e Paraíba. O primeiro questionário estava centrado na fala do Jornal Nacional e buscava verificar se os entrevistados acreditavam que, entre outros tópicos, a fala dos jornalistas desse jornal se assemelhava à fala de sua região de origem ou à sua própria. $\mathrm{O}$ segundo questionário foi aplicado a 33 moradores de Minas Gerais e consistiu em ouvir fragmentos de entrevistas e em classificar os falantes dessas gravações em relação à origem e profissão. Além dessas duas características, Ramos (1997) também questionou seus entrevistados se a fala das gravações era agradável e correta. Em seus resultados, o dialeto paulista é avaliado pelos entrevistados como uma das pronúncias "mais corretas do Brasil" (RAMOS, 1997, p. 116-118).

A explicação para a variedade de língua paulista ter sua avaliação modificada, do Brasil Império aos dias atuais, pode residir em fatores socioeconômicos, mas quando alguns traços dessa variedade de língua teriam sido eleitos como o padrão para o telejornalismo nacional? Exploraremos alguns fatores socioeconômicos que ajudarão a balizar esse percurso da variedade de fala paulista. O que se sabe, também, é que o processo de padronização e gramaticalização das línguas acompanha o desenvolvimento socioeconômico de seus povos. A instalação da Faculdade de Direito nos parece ser um dos pontos sociais em que o processo de padronização da fala paulista se inicia.

Outro ponto interessante de se observar é que a instalação da faculdade na cidade de São Paulo não é o único marco relacionado a instituições de ensino em terras paulistas. Como mencionado por Gomes (2010), a preocupação do Império em relação 
à instrução gramatical dos brasileiros surgiu na mesma época dos debates da Constituinte de 1823: em 05 de março de 1823, é publicado um decreto que cria uma "cadeira de grammatica latina para instrucção da mocidade" (BRASIL, 1887, p.43); e, em 15 de outubro de 1827 (mesmo ano em que as duas primeiras faculdades de Direito do país são inauguradas), é sancionado o Decreto Imperial que determinava que "todas as cidades, vilas e lugarejos tivessem suas escolas de primeiras letras" (BRASIL, 1878, p. 71). Muitas regiões do Brasil, naquela época, ainda possuíam uma língua geral para comunicação, o que também serviu como motivo para a criação destes decretos.

De forma a entender o que foi classificado por "fala errada", objetiva-se, primeiramente, verificar como gramáticos e historiadores registraram ou comentaram traços fonéticos da fala paulista com o passar dos tempos, tentando realizar um comparativo que se inicia na época do Império até o início da criação da região metropolitana de São Paulo (por volta de 1970). A escolha desse segundo momento se dá pelo fato de que as estradas e conexões entre as cidades próximas a São Paulo fariam com que as formas linguísticas circulassem mais pelo território, uma vez que seus moradores poderiam se deslocar de uma área à outra com maior facilidade. Em seguida, busca-se entender como a expansão da cidade de São Paulo se deu após a instalação da Faculdade de Direito. Dados demográficos e os processos de urbanização pelos quais a cidade passou podem auxiliar a observar a importância da faculdade para a relação dos indivíduos com a língua e ajudar a entender como traços da variedade de fala paulista tiveram seu espalhamento para a mídia.

\section{O sotaque paulista através dos anos}

Observar as características da fala de uma determinada comunidade, em tempos pretéritos, é uma tarefa difícil, pois nem sempre é possível que se tenha acesso aos registros de fala da época. Uma maneira de verificar como as variedades de fala eram caracterizadas é pelos comentários de gramáticos da época e pelos relatos de viajantes estrangeiros ao Brasil. Dessa maneira, é possível obter detalhes sobre as formas linguísticas usadas anteriormente - como veremos a seguir, em relação à fala da província de São Paulo. 
Em 1847, o viajante Saint-Hilaire (1851a e 1851b) peregrinou pelo Brasil e visitou, entre outras regiões, a província de São Paulo. Em seus relatos, descrições das regiões brasileiras são feitas e, em termos linguísticos, interessa-nos, em especial, uma delas:

Não surpreende, portanto, que, apesar de sua profunda ignorância, os habitantes dos Campos Geraes falem o português muito mais corretamente do que os da cidade de São Paulo, e o pronunciam melhor; por exemplo, não pronunciam o "ch" como "ts", nem o "g" como "dz": essas alterações foram introduzidas pelos índios em língua portuguesa, e os colonos dos bairros de Castro e Curitiba estavam pouco misturados com os nativos (SAINT-HILAIRE, 1851b, p. 7-8. Grifos nossos. Tradução nossa' ${ }^{1}$.

Dois processos fonéticos são observados no trecho acima: a passagem da fricativa [J], grafada como “ch", à variante dental alveolar desvozeada [ts], grafada como "ts"; e a passagem da velar [g] à variante dental alveolar vozeada [dz]. O primeiro processo fonético aqui mencionado é também descrito por Amaral (1920, p. 22): “ch" e “j” palatais: são "explosivos", como "no Inglês (chief, majesty)"; ou seja, é um traço característico do "dialeto caipira".

Em outra comparação com a região Sul do país, Saint-Hilaire (1851b) deixa claro que a formação do povo sulista não poderia ter se dado da mesma maneira que a mescla da população paulista e uma dessas razões seria o português claro que falavam:

\begin{abstract}
Aqui surge naturalmente uma questão de que não será sem interesse procurar resolver: de onde vieram os homens que primeiro povoaram Curitiba, seu distrito e os Campos Geraes? Pertencendo, em sua maior parte, à raça caucasiana perfeitamente pura, pronunciando o português sem qualquer alteração, os atuais habitantes desses países não podem obviamente descender de seus vizinhos os mestiços dos distritos de Itapitininga e Itapéva. Também não se pode supor que eles vieram de uma colônia proveniente da capital da capitania; pois, nesse caso, eles também carregariam marcas de uma mistura de sangue índio, já que os Mamalucos compunham de maneira muito ampla as bandas que de S. Paulo se espalharam nos desertos da América. (SAINT-HILAIRE, 1851b, p. 117. Grifos nossos. Tradução nossa²).
\end{abstract}

\footnotetext{
1 II ne faut donc pas s'étonner si, malgré leur profonde ignorance, les habitants des Campos Geraes parlent le portugais beaucoup plus correctement que ceux du voisinage de la ville de S. Paul, et s'ils le prononcent mieux; si, par exemple, ils ne prononcent pas le ch comme ts, ni le g comme dz: ces altérations ont été introduites par les Indiens dans la langue portugaise, et les colons des districts de Castro et de Curitiba se sont peu mêlés avec les indigenes.

${ }^{2}$ Ici s'éleve naturellement une question qu'il ne sera pas sans intérêt de cherchér à résoudre·: d'ou venaient les hommes qui les premiers ont peuplé Curitiba, son district et les Campos Geraes? Appartenant, pour la plupart, à la race caucasique parfaitement pure, prononçant le portugais sans aucune altération, les habitants actuels de ces pays ne peuvent évidemment descendre de leurs voisins les métis des districts d'Itapitininga et d'Itapéva. On ne peut non plus supposer qu'ils soient issus d'une colonie venant de la capitale de la capitainerie; car, dans ce cas, ils porteraient également des marques d'un mélange de sang indien, puisque les Mamalucos composaient en trés grande pattie les bandes qui de S. Paul se répandaient dans les déserts de l'Amérique.
} 
Mais adiante, em sua obra, ressalta mais uma vez a característica do "bom português", na fala dos sulistas: "Em nenhuma parte do Brasil havia tantos homens verdadeiramente brancos como no distrito de Curitiba. O povo deste país fala português sem nenhuma das alterações que mencionei em outro lugar" (SAINTHILAIRE, 1851b, p. 134. Tradução nossa3).

Em 1867, o capitão inglês Richard Burton realizou, dentre suas inúmeras viagens pelo globo terrestre, uma exploração em diferentes regiões do Brasil. Sua obra (BURTON, 1869) teve como objetivo descrever a dinâmica das minas de ouro em algumas regiões do país. O autor também almejou descrever o rio São Francisco e seu funcionamento em termos de transporte fluvial. Sua viagem é feita 44 anos após os debates da Constituinte de 1823 e traz, em determinados momentos, comentários que interessam a nós, linguistas. Pensando na questão do dialeto paulista, Burton (1869, p. 48. Tradução nossa4), ao descer um rio no estado do Rio de Janeiro, narra: "Nosso barco quase chegou a virar em uma volta, ou uma dobra, forte um pouco abaixo da Barra do Diamante". Há um destaque para a palavra "volta" - escrita em português em seu relato, em que é dito o seguinte, em nota de rodapé:

Geralmente pronunciada em Minas e São Paulo como "vorta", a confusão do "r" e do "l" são comuns como na China, e eu cheguei a escutar um "Universitário" e um Delegado da Província chamar a Estrella da Alva (estrela da manhã) como Estrera da Arva. Como dito, muitos dos "Índios" não conseguem articular o "l". Além disso, em Tupy é popularmente sabido que "f", "r" e "l" são faltosos. Isso, entretanto, não aparece na Língua Geral, que ignora o "d", "f", "h" e "l" (BURTON, 1869, p. 48. Tradução nossa5).

A descrição acima nos chama atenção para o fenômeno destacado por Burton: o rotacismo ${ }^{6}$, que também é descrito por Amaral (1920) e Rodrigues (1974) nas populações do interior do estado de São Paulo, cuja variedade dialetal é o "dialeto

\footnotetext{
${ }^{3}$ Dans aucune partie du Brési n'avais vu autant d'hommes véritablement blancs que dans le district de Curitiba. Les habilants de ce pays prononcent le portugais sans aucune de ces altérations dont j'ai parlé ailleurs.

${ }^{4}$ Our awning nearly came to grief at a sharp volta or bend a little below the Barra do Diamante.

5 Usually pronounced in Minas and Sao Paulo "Vorta." The confusion of the "r" and "l" are as common as in China, and I have heard a "University man" and a Provincial Deputy call the Estrella da Alva (the morning star) Estrera da Arva. As has been said, many of the "Indians" cannot articulate the I. Moreover, in Tupy it is popularly asserted that $f, r$, and I are wanting. This, however, certainly does not appear in the Lingoa Geral, which ignores $d, f, h$, and $\mathrm{l}$.

6 O fenômeno do rotacismo é apontado, também, por Saint-Hilaire (1851a, p. 456-457) nos falantes da Língua-Geral, mais precisamente nos índios Guaianases que habitavam parte da região paulista: sua palavra para "água" seria "goió", com a observação do autor ao dizer que o último "ó" é aberto como na palavra "or", e na palavra "clingloforce", que significaria "lambarí", em que os dois "l" seriam realizados com o som de "r".
} 
caipira”. A diferença, aqui, está no fato de Burton destacar que um universitário e um funcionário do governo, supostamente de maior nível de instrução (de acordo com o autor), também realizariam o rotacismo em suas falas. Outra menção à pronúncia é feita por Burton (1869, p. 49. Tradução nossa7), também ao descrever um percurso feito ao longo de um rio: “Após a 'dobra do Tapir', deparamo-nos com um Funil - aqui, assim como em São Paulo, pronunciado como Funí”. O fenômeno aqui observado pode se referir à apócope, a supressão de um ou mais fonemas no final de uma palavra, também apontado por Amaral (1920) no “dialeto caipira”.

Ao comentar sobre sua viagem pelas águas de Pirapora, há outro comentário de Burton (1869, p. 199. Tradução nossa ${ }^{8}$ ) sobre a fala paulista: "No Tietê [rio], em São Paulo, as pessoas o traduzem como 'Sinal de peixe', fazendo 'Pora', uma corrupção de 'Bora”'. O fenômeno linguístico aqui descrito nos parece como a alternância entre a realização da oclusiva labial vozeada [b] para uma realização desvozeada [p], o que é colocado por Burton como uma "fala corrompida" do vocábulo original.

Outros comentários feitos por Burton (1869) em sua obra nos auxiliam a verificar o prestígio que cada região do país tinha na época. Esses comentários são feitos sob a perspectiva de um capitão inglês que foi ao Brasil descrever suas minas de ouro e recursos naturais, como fauna e flora. Precisamos ter isso em mente ao ler seus relatos, que têm uma finalidade voltada à descrição da capacidade econômica dos territórios. Sendo assim, seus relatos, muitas vezes, comparam uma região a outras. Por exemplo, Burton (1869, p. 89) menciona que São Paulo é uma cidade extremamente cara por conta do preço de um alqueire na região. Em uma comparação entre a região da Bahia e São Paulo, aponta o seguinte:

Fiquei espantado com a ausência de todos os progressos nesses locais ocidentais da grande província baiana, cuja principal cidade já foi à metrópole do país e cujo litoral é hoje uma das porções mais prósperas e populosas do Império. Tudo o que vemos denota pobreza, maldade e negligência; uma Fazenda no interior de São Paulo ou de Minas é igual a uma cidade daqui; e enquanto o majestoso São Francisco corre diante desses casebres, e há excelentes linhas para rotas tanto para o mar como para o interior, o povo ignorou completamente suas comunicações (BURTON, 1869, p. 300. Tradução nossa ${ }^{9}$.

\footnotetext{
${ }^{7}$ After the "Tapir's bend" we at once came to the Funil-here, as in Sao Paulo, pronounced Funí.

${ }^{8}$ On the Tiete, in Sao Paulo, the people translate it "Sign of fish," making "Pora" a corruption of "Bora".

${ }^{9}$ I was astonished at the absence of all progress in these western outstations of the great Bahian Province, whose chief city was once the metropolis of the country, and whose seaboard is now one of the most prosperous and populous portions of the Empire. Everything that we see denotes poverty,
} 
O comentário acima se relaciona a questões de infraestrutura entre as duas cidades, sendo, na visão do capitão, a cidade de São Paulo mais bem preparada para receber pessoas vindas de fora. Ainda em relação à Bahia ${ }^{10}$, Burton (1869, p. 319. Tradução nossa") faz um comentário sobre o povo que ali habita: "Achei-os gentis e corteses, como é realmente a regra no Brasil, mas o Baiano não se destacou mais que o Paulista, ou que o Mineiro”. Já em outro comentário, há a comparação entre pernambucanos e paulistas que enaltece os moradores de São Paulo:

O grupo consistia dos piores homens, das piores bestas e dos piores equipamentos que eu havia visto no Brasil; e a decepção foi maior, já que a Fama há muito fala alto em favor dos "tropeiros" de Pernambuco. Se estes forem espécimes justos, dois deles não valem um paulista ou um mineiro (BURTON, 1869, p. 436. Tradução nossa' ${ }^{12}$.

Há uma simpatia, da parte de Burton (1869), para com os paulistas, até mesmo nos momentos em que comenta sobre o fracasso de suas plantações de algodão e a frustração com os poucos diamantes encontrados na região. Saint-Hilaire (1851a) também faz menção à coragem dos paulistas:

Por mais perseverantes que fossem os intrépidos, os antigos paulistas enfrentaram todos os perigos; não temiam nem as flechas do selvagem, nem a fome, nem a queda das estações, nem a falta de repouso, nem as privações de toda espécie, nem mesmo as doenças pestilentas, que, no entanto, devoraram, em meio a esses desertos, muitos de seus antecessores. (SAINT-HILAIRE, 1851a, p. 36o. Tradução nossa ${ }^{13}$ ).

O que nos parece ser ressaltado nos comentários acima, comparando os moradores de diferentes regiões, é o estilo de vida dos paulistas, que é elucidado por Ribeiro (2006):

meanness, and neglect; a Fazenda in the interior of Sao Paulo or of Minas is equal to a town here; and whilst the majestic Sao Francisco flows before these hovels, and there are excellent lines for routes both to the seaward and to the interior, the people have wholly ignored their communications.

10 Há um comentário sobre a pronúncia na Bahia: "The higher parts of the bank showed us on the opposite, or Bahian side, "Olho d'Agua" pronounced " Oidá "-a fine hillblock some 800 to 900 feet above sea level" (BURTON, 1869, p. 434. Grifos nossos). O fenômeno, aqui apontado por Burton, parece-nos tratar da vocalização da consoante lateral palatal.

11 I found them civil and courteous, as indeed is the rule of the Brazil, but the Bahiano did not shine after the Paulista, or the Mineiro.

12 The party consisted of the worst men, the worst beasts, and the worst equipments that I had seen in the Brazil ; and the disappointment was the greater as Fame has long spoken loudly in favour of the "tropeiros" of Pernambuco. If these be fair specimens, two of them are not worth one Paulista, or Mineiro.

${ }_{13}$ Aussi persévérants qu'intrépides, les anciens Paulistes bravaient tous les dangers; ils ne eraignaient ni la flêche du sauvage, ni la faim, ni les intempéries des saisons, ni le manque de repos, ni les privations de tout genre, ni même les maladies pestilentielles, qui pourtant avaient dévoré, au milieu de ces déserts, un si grand nombre de leurs devanciers. 
assim, num tempo em que as nações deserdadas na divisão do mundo apelavam para a pirataria marítimas dos corsários, os paulistas, que eram os deserdados do Brasil, lançavam-se, também, ao saque com igual violência e cobiça. Marginalizados do processo econômico da colônia em que quase todos estavam voltados para as lucrativas tarefas pacíficas dos engenhos e dos currais de gado, os paulistas acabaram por se especializar como homens de guerra. (RIBEIRO, 2006, p. 333. Grifos nossos).

De fato, o destaque dado aos paulistas reside na ideia de que este povo não faz parte de uma região urbanizada ou de alta civilidade. O que é ressaltado é o estilo de vida rudimentar, mas eficiente em termos de subsistência. Em trechos em que discorre sobre a exploração de diamantes no Brasil, Burton (1869, p. 133. Tradução nossa'4) aponta que a região central do país seria a mais simpática, em termos sociais: "Deixei a região da Diamantina, o que inclui a mina do Duro, com pesar. Em termos sociais, essa é a região mais simpática do Brasil, de acordo com minha experiência". Já outras regiões, como Minas Gerais, não teriam moradores tão educados (BURTON, 1869, p. 193).

Estes são relatos de viajantes no Brasil. Outra fonte que podemos consultar, de forma a tentar entender o que se passou com o dialeto paulista/paulistano, são as gramáticas. Estamos tratando, de certa maneira, com fenômenos fonéticos da língua portuguesa no Brasil e as gramáticas nem sempre abordam este tema. O quadro abaixo apresenta as principais obras publicadas na virada do século XIX para o XX, que é nosso ponto de partida para nossa pesquisa em instrumentos linguísticos da época:

Tabela 1: Quantificação e distribuição de dados fonéticos, morfológicos, lexicais e sintáticos do PB presentes em textos gramaticais brasileiros do século XIX

\footnotetext{
${ }^{14}$ I left the Diamantine region, including the Duro mine, with regret. Socially speaking, it is the most
} sympathetic spot in Brazil, according to the light of my experience. 


\begin{tabular}{c|c|c|c|c|c|c}
\hline FENOMENOS & Fonéticos & Morfológicos & Lexicais & Sintáticos & Gerais & TOTAL \\
\hline OBRAS & 0 & 0 & 0 & 1 & 0 & 1 \\
\hline Morais Silva (1806) & 0 & 0 & 0 & 0 & 0 & 0 \\
\hline $\begin{array}{c}\text { Coruja (1835) } \\
\begin{array}{c}\text { Sotero dos Reis } \\
\text { (1866) }\end{array}\end{array}$ & 0 & 0 & 0 & 0 & 0 & 0 \\
\hline $\begin{array}{c}\text { Carneiro Ribeiro } \\
(1877)\end{array}$ & 3 & 0 & 4 & 2 & 0 & 9 \\
\hline Ribeiro (1881) & 4 & 1 & 0 & 13 & 0 & 18 \\
\hline $\begin{array}{c}\text { Pacheco e Lameira } \\
(1887)\end{array}$ & 3 & 3 & 6 & 3 & 3 & 18 \\
\hline Ribeiro (1889[1887]) & 1 & 0 & 3 & 1 & 2 & 7 \\
\hline $\begin{array}{c}\text { Carneiro Ribeiro } \\
(1890)\end{array}$ & 3 & 0 & 4 & 2 & 0 & 9 \\
\hline Maciel (1902[1894]) & 2 & 2 & 4 & 5 & 0 & 13 \\
\hline $\begin{array}{c}\text { Said Ali } \\
\text { (1919[1908]) }\end{array}$ & 1 & 0 & 0 & 1 & 1 & 3 \\
\hline
\end{tabular}

Fonte: Polachini e Danna (2016, p. 193)

Conforme disposto acima, a primeira gramática a contemplar traços fonéticos data de 1877. Partindo dessa data e dos autores mencionados no quadro anterior, comentaremos, a seguir, algumas observações fonéticas de algumas dessas gramáticas. A primeira observação que nos interessa é feita por Ribeiro (1881, p.9) ao não reconhecer [ts] e [dz] como sons da língua portuguesa. Vale lembrar que Saint-Hilaire (1851b, p. 7-8) - como mencionado no início desta seção - aponta estes dois sons como características da fala dos paulistas. Em seguida, Ribeiro (1881) faz um comentário sobre a fala dos "caipiras de São Paulo":

Ha mais dous sons distintos banidos hoje do uso da gente culta: dje, tche.

Os caipiras de S. Paulo pronunciam djente, djogo. Os mesmos e também os Minhotos e Trasmontanos dizem tchapéo, tchave.

F. Diez pensa que dje, tche são as fôrmas primitivas de je e che, e tudo leva a crêr que realmente o são.

Dje é som romanico genuíno; existe em Provençal, em Italiano, e no século XIII existia no Francez que o transmittiu ao Inglez, onde até agora se acha, ex.: «jealousy». Em escriptos latinos do século IX encontram-se as fôrmas pegiorentur, pediorentur, por pejorentur.

Tche é também som romanico castiço: existe em Provençal, em Italiano, em Hespanhol, e existiu no Francez, donde passou para o Inglez que ainda hoje o conserva, ex.: «chamber».

A existencia de ambas estas fôrmas no fallar do interior do Brazil prova que estavam ellas em uso entre os colonos portuguezes do século XVI. A antigüidade e a vernaculidade do tche attestam-se pela sua permanencia na linguagem do Minho e de Trás-os-Montes: como sabe-se, o povo rude é conservador tenaz dos elementos arkhaicos das linguas (RIBEIRO, 1881, p. 11. Grifos nossos). 
O gramático ainda faz menção a outros fenômenos ${ }^{15}$ usados pelos "caipiras de São Paulo":

1) A omissão do pronome relativo "que" (RIBEIRO, 1881, p. 222);

2) O uso de expletivos para verbos que tratam de fenômenos da natureza: "Elle chove muito lá" (RIBEIRO, 1881, p. 293);

3) A acentuação da primeira sílaba do verbo "poder" quando do caráter impessoal: "Póde que chova" (RIBEIRO, 1881, p. 294);

4) O uso de dupla negação (RIBEIRO, 1881, p. 30o);

5) E o uso da preposição "de" junto a locuções que utilizam a preposição "a": "Vou de a pé" (RIBEIRO, 1881, p. 303).

É interessante verificar que no ano de 1881 já há uma divisão, feita pelo gramático, para os "caipiras" de São Paulo; o que implica que aqueles que assim não falam não seriam classificados como tal - há, então, dois grupos de indivíduos em São Paulo. Os relatos de Burton (1869) mostravam rotacismos feitos por pessoas de alto nível de instrução, mas não há, em seus relatos, uma divisão entre "caipiras" e "não caipiras".

Carneiro Ribeiro (1890) faz algumas observações sobre fenômenos fonéticos que são observados no "dialeto caipira" por Amaral (1920) e Rodrigues (1974). O primeiro deles diz respeito à permuta de [l] por $[\mathrm{r}]$ :

\begin{abstract}
A afinidade dos sons notados por esses dois caracteres graphicos ["l" e "r"] na lingua fallada ainda se demonstra não só pelo facto de alguns idiomas, que não possuem o $\mathrm{r}$, o substituírem na pronuncia pelo 1 , senão também pela confusão e troca de um som por outro na pronuncia do povo [...] Muitos indivíduos ha, finalmente, em que se nota este vicio de pronuncia, de que muitas vezes é locado mais de um membro da mesma familia (CARNEIRO RIBEIRO, 189o, p. 59. Grifos nossos).
\end{abstract}

Sobre a apócope, observada no "dialeto caipira", Carneiro Ribeiro (1890, p. 37) diz: "é facto muito vulgar na formação não só de nossa lingua, senão também na de todos os idiomas românicos". Há menção desses dois processos linguísticos como

\footnotetext{
${ }^{15}$ É curioso verificar que os "caipiras" são mencionados como indivíduos que empregam formas "complicadas e corretíssimas" do modo subjuntivo, enquanto que muitos estrangeiros não o conseguiriam fazer (RIBEIRO, 1881, p. 268). É interessante observar que, em tempos atuais, como registrado por Oushiro (2015), determinadas características fonéticas atribuídas aos "caipiras" do interior do estado de São Paulo são encontradas na cidade de São Paulo. Um desses exemplos é o uso da variante retroflexa para a realização de /r/ em posição de coda-silábica. Contudo, nos bairros centrais da cidade, Oushiro (2015) registra que a variante tepe é encontrada com maior frequência do que a retroflexa. Assim, traços "caipiras" coexistem com traços "urbanos".
} 
pertencentes ao falar do "povo". A seção sobre fonética deste gramático não traz outros comentários acerca de comunidades que praticam uma ou outra forma variante, concentrando-se em explicar a origem dos sons e a maneira pela qual são encontrados na língua portuguesa. Por fim, esse autor faz algumas observações sobre a realização das vogais átonas no português paulista:

Do Rio de Janeiro para o sul os sons das vozes, e, o vão se tornando de mais a mais agudos. Assim no Rio se pronunciam as locuções adverbiadas - de tarde, de noite, de manhã, apparecer, desapparecer, como se fossem escriptas dé noite, dé tarde, dé manhã, apparécer, desapparécer.

Essa acuidade de sons, já sensível na capital dos Estados Unidos do Brazil, torna-se muito mais notável em S. Paulo e no Rio Grande do Sul, onde se ouvem as expressões - dê noite, dê tarde, dê manhã, fêche, côllegio, dè pressa, côpinho, môderno, um conto dê réis (CARNEIRO RIBEIRO, 189o, p. 846).

Maciel (1902 [1894]), em uma pequena subseção de sua "Grammatica Descriptiva" intitulada "corrupção phonetica":

corrupção phonetica ou cacoepia [que] é o estrago por que passa o vocabulo nos seus sons constitutivos sob a acção da pronuncia popular das classes illetradas. Assim se observam as corrupções - binho por vinho, borços por bolços, colmejo por colmeia, em que o vocabulo se desviou da forma clássica (MACIEL, 1902 [1894], p. 49-50).

O exemplo da palavra "bolsos" realizada foneticamente como "borsos" mostra um caso de rotacismo, mais uma vez atribuído como típico da "pronúncia popular das classes iletradas”.

Said Ali (1964 [1931]) em sua obra "Gramática Histórica da língua portuguesa", não faz menção direta ao termo "caipira" ou aos paulistas, mas destaca, em sua seção sobre "a realização dos sons", o seguinte sobre a permuta de "l" por "r":

Não duraria muito a phase da surpresa. Com o descostume do falar indigena e o exercicio da pronuncia na acquisição de novos vocabulos lations, a dificuldade devia estar vencida mais ou menos na segunda geração. Não se reformou comtudo a maneira de proferir certos termos de uso diario (a maior parte dos supra-mencionados), que desde logo se arraigaram, obliterando-se da memoria a sua connexão com as respectivas expressões latinas. Naquella palavras que cedo se introduziram em portuguez com os grupos consonantaes latinos, observa-se a frequente troca de 1 por r. (SAID ALI, 1964 [1931], p. 84. Grifos nossos).

O contato entre línguas indígenas e a língua portuguesa é, novamente, apontado como uma das causas para o surgimento de variantes observadas no "dialeto 
caipira" da região paulista. Neste caso, o rotacismo é destacado. É interessante observar nas gramáticas aqui comentadas que as alusões às "classes iletradas", ao "povo", ou, de forma mais direta, aos "caipiras" apresentam exemplos de "má pronúncia". Esses comentários sobre a língua, presentes nas gramáticas e nos relatos de viagem, explicam a fala do deputado Lúcio Teixeira, em 1823, sobre o dialeto paulista ser o "menos correto". Outro ponto interessante é que a menção ao "caipira" é feita somente na gramática de Ribeiro (1881), no ano de 1881, o que nos leva a crer que há um acontecimento socioeconômico próximo a essa data que marca a divisão do interior do estado de São Paulo e de suas zonas metropolitanas. Anos após, o trabalho de Amaral (1920), no ano de 1920, já apresenta o caipira como "isolado" no interior do estado.

Considerando os relatos de Saint-Hilaire (1851a e 1851b) e de Burton (1869), bem como os estudos sobre o "dialeto caipira" de Amaral (1920) e Rodrigues (1974), parecenos que a variedade dialetal em voga na cidade de São Paulo, em 1823, era o "dialeto caipira”. Não são muitos os traços fonéticos descritos por estes viajantes, contudo as variantes por eles destacadas são as mesmas elucidadas em estudos sobre o "dialeto caipira”. Dessa maneira, isso também nos leva a refletir cronologicamente: em 1920, Amadeu Amaral apresenta o dialeto caipira como a variedade de fala de indivíduos que se encontram em locais dispersos e afastados dos centros urbanos. Tal fato nos leva a crer que a variedade paulistana de fala padrão por volta de 1870 é, cinquenta anos depois, substituída por outra (ou transformada em outra por um processo de mudança linguística), uma vez que essa fala só seria encontrada em indivíduos em regiões afastadas. Cerca de cinquenta anos após o estudo de Amaral (1920), por volta de 1970, traços do dialeto paulista seriam selecionados para compor a fala dos apresentadores do Jornal Nacional (como mencionado na introdução deste trabalho). Quais são os acontecimentos socioeconômicos entre 1870 e 1920 que impulsionaram a transformação do dialeto paulista? Parece-nos que tal acontecimento está relacionado à urbanização (estabelecendo a divisão entre o caipira e o não-caipira). E, por fim, quais são os acontecimentos entre 1920 e 1970 que alçam alguns traços dessa variedade dialetal a nível nacional por meio dos telejornais?

\section{A mudança de um dialeto}


Pode-se pensar no dialeto paulistano da década de 1820 como fruto do contato entre as línguas do colonizador, dos índios e dos escravos africanos. Com isso, surge uma língua-geral paulista pela qual esses três grupos se comunicam. Em 18o8, outro viajante, John Mawe (1978, p. 64), aponta que havia uma população entre 15 mil e 20 mil pessoas na cidade de São Paulo. Já em 1836, Marcílio $(1974$, p. 12) afirma que a população paulistana seria composta por 21.933 habitantes. O grande fluxo de estrangeiros no final do século XIX, principalmente o de portugueses, é um dos fatores (junto a outros, como as políticas linguísticas do Marquês de Pombal - implementadas em meados do século XVIII) que faz com que a língua-geral perca espaço para a língua portuguesa:

\begin{tabular}{cccccc}
\multicolumn{7}{c}{ Tabela 2: Residentes em São Paulo (1872 a 2000) } \\
Anos & $\begin{array}{c}\text { População } \\
\text { Total }\end{array}$ & $\begin{array}{c}\text { Brasileiros } \\
\text { Batos }\end{array}$ & $\begin{array}{c}\text { Brasileiros } \\
\text { Naturalizados }\end{array}$ & Estrangeiros & $\begin{array}{c}\text { Nacionalidade } \\
\text { Não Declarada }\end{array}$ \\
\hline 1872 & 31.385 & - & - & 2.459 & - \\
1890 & 64.934 & - & - & 14303 & - \\
1900 & 239.820 & - & - & - & - \\
1920 & 579.033 & 372.376 & - & 205.245 & 1.412 \\
1940 & 1.326 .261 & 1.029 .047 & 11.176 & 285.469 & 569 \\
1950 & 2.198 .096 & 1.881 .362 & 16.159 & 300.430 & 145 \\
1960 & 3.781 .446 & - & - & - & - \\
1970 & 5.924 .615 & 5.506 .071 & 36.847 & 381.697 & - \\
1980 & 8.493 .226 & 8.112 .464 & 55.213 & 325.540 & 9 \\
1991 & 9.646 .185 & 9.405 .725 & 42.050 & 198.410 & - \\
2000 & 10.434 .252 & 10.239 .905 & 40.735 & 154.906 & - \\
\hline
\end{tabular}

Fonte: Adaptado de IBGE (2018), Censos Demográficos

No ano de 1872, os três maiores grupos de estrangeiros eram compostos por: portugueses, com 966 habitantes; africanos (escravos), com 474 habitantes; e alemães, com 420 habitantes. Mais da metade destes grupos se encontravam na região do primeiro bairro urbanizado da cidade, o bairro da Sé (IBGE, 2018), com 9.253 habitantes na pequena área de $2,1 \mathrm{~km}^{2}$, como disposto na figura mais adiante. No total, cerca de 1.200 imigrantes moravam no bairro da Sé (IBGE, 2018) no ano de 1872.

Assim, a variedade de língua paulista passa por outros contatos, em especial o contato entre a variedade de língua paulistana e a variedade de língua lusitana. $\mathrm{O}$ contato entre dialetos foi estudado por Trudgil (1986) que apontou três estágios importantes dessa situação de contato linguístico: há, entre os falantes de duas ou mais variedades de uma língua, um processo de mistura [mixing]. Após, há o nivelamento [levelling] das variantes de determinada variável linguística, em que há a "redução ou o 
atrito de variantes marcadas" (TRUGILL, 1986, p. 98). Por fim, há o processo de simplificação, em que há um "aumento na regularidade” de uma variante (TRUDGILL, 1986, p. 103). As variantes podem, também, ser realocadas, fazendo com que uma ou outra carregue consigo significação social.

Kerswill e Trudgill (2005) apontam que a mistura, nivelamento e simplificação de formas variantes dão origem à koinetização, ou seja, uma regionalização de uma variedade de fala. Esse procedimento pode levar à focalização [focusing] de formas, fazendo com que a fala dentro de uma comunidade se estabilize, com a diminuição de variantes para determinadas variáveis linguísticas.

Outro ponto interessante é pensar que, em 1872, a população paulistana contava com 11.793 habitantes - de seus 31.358 moradores - de idades entre o e 14 anos - quase um terço de sua população (IBGE, 2018). Como apontado por Siegel (2010), falantes mais jovens - de sete anos ou menos - estão sujeitos a adquirirem mais rapidamente novas formas fonéticas e os falantes de 14 anos ou menos estão sujeitos à aquisição de formas morfossintáticas. Em situações de contato dialetal, o fator "idade de aquisição" é o mais importante para a convergência a determinada variedade de fala.

Uma região pequena, com grande diversidade de variedades de fala e com muitos habitantes jovens é um cenário propício para que o contato entre dialetos resulte em mudança linguística. A região central da cidade de São Paulo, que engloba as regiões da Sé, República e arredores, é lar para a Faculdade de Direito de São Paulo de onde a urbanização da cidade se iniciou.

\section{A sócio-história paulistana}

Colocar os eventos acima em uma ordem cronológica auxilia a entender a transformação do dialeto paulistano: (i) o dialeto paulista é avaliado negativamente, em 1823; (ii) relatos de viajantes mostram, entre as décadas de 1840 e 1860, que muitas formas consideradas por Amaral (1920) como próprias do dialeto caipira eram a fala padrão dos paulistanos. Tal fato estaria ligado à diversidade do povo paulistano: a mistura entre colonizadores, indígenas e escravos africanos que resultaria em um dialeto diferenciado do resto do país; (iii) a divisão entre o urbano e o caipira é feita por Ribeiro (1881), em sua gramática, no ano de 1881. Isso indica que a fala paulistana, 
em sua área urbana, já não é mais caracterizada pelos traços encontrados na fala dos caipiras que vivem em regiões mais afastadas dos centros urbanos; (iv) a fala dos moradores do interior do estado de São Paulo é retratada, em 1920, em um estudo sobre o "dialeto caipira” (AMARAL, 1920). Aqui a divisão entre os moradores das cidades e aqueles do campo já é bem definida; e (v) alguns traços da fala paulistana são adotados, por volta de 1970, como exemplos de pronúncia a serem utilizados por apresentadores de telejornais de grande abrangência a nível nacional.

Entre os anos de 1820 e 1870 , diferentes fatores fizeram com que a fala paulista apontasse para uma direção diferenciada. O período de cinquenta anos que segue essa transformação caracteriza-se pela formação da área urbana de São Paulo, criando a diferença entre moradores da cidade e do campo. Cinquenta anos depois, a consolidação de São Paulo e suas regiões metropolitanas como uma forte metrópole fazem com que, no início da década de 1970, formas linguísticas da capital circulem com maior facilidade. Alguns fatores sócio-históricos podem estar correlacionados às forças que guiaram esta mudança dialetal. Vejamos isso nos três períodos de tempo citados acima.

\section{Os anos de 1820 a 1870}

A instalação da Faculdade de Direito em São Paulo, bem como a instituição das “escolas de primeiras letras" nas vilas e vilarejos brasileiros, faz com que exista maior preocupação no uso da linguagem. Matos (1955, p. 103) apontou a Faculdade de Direito como a responsável por "expandir [a cidade] de maneira sempre crescente e imprevisível, [que] viu alterar-se seu ritmo de vida, passou a conhecer funções novas, modernizou-se, num caminho rápido e seguro para o espetacular crescimento registrado no século atual". A faculdade é colocada como um dos motivos centrais para a expansão da cidade de São Paulo e isso implica na vinda de pessoas para ela. Matos (1955) também diz o seguinte sobre a demografia da cidade de São Paulo no ano de 1830:

das 10 freguesias que constituiam o têrmo da cidade apenas três correspondiam ao centro urbano: Sé, Santa Ifigênia e Brás, englobando um total de apenas 9.391 habi-tantes, o que significa bem menos da metade da população recenseada. A maior parte da gente paulistana espalhava-se pelas demais freguesias, que seriam os subúrbios da Paulicéia de então: Guarulhos, 
Nossa Senhora do Ó, Cotia, Nossa Senhora da Penha, São Bernardo, Juquerí e MboY (Embú). Por conseguinte, não chegaria a 10.000 habitantes a população urbana de São Paulo ao findar a terceira década do século XIX, encontrandose assim distribuida: Sé, 5.668 [habitantes]; Santa Ifigênia, 3.064 [habitantes]; e Brás, 659 [habitantes] (MATOS, 1955, p. 94).

Muller (apud Matos, 1955, p. 96) destaca características similares da população paulistana, na primeira metade do século XIX, que permitem pensar sobre o contato entre dialetos nesta região:

Tabela 3: Habitantes da cidade de São Paulo na primeira metade do século XIX

\begin{tabular}{|c|c|c|c|c|}
\hline $\begin{array}{l}\text { Sé } \ldots \ldots \\
\text { Santa Ifigênia } \ldots \\
\text { Brás .......... }\end{array}$ & $\begin{array}{c}\text { Brancos } \\
2.557 \\
1.196 \\
328\end{array}$ & $\begin{array}{r}\text { Pardos } \\
1.085 \\
1.067 \\
175\end{array}$ & $\begin{array}{r}\text { Pretos } \\
1.935 \\
739 \\
156\end{array}$ & $\begin{array}{c}\text { Indio } \\
1 \\
62 \\
-\end{array}$ \\
\hline Totais: & 4.081 & 2.327 & 2.830 & 63 \\
\hline
\end{tabular}

Os números acima mostram que a presença de mestiços (pardos) era grande na população paulistana. Em relação à população escrava, Rocha (2009, p. 23) aponta que, em 1829, havia 3139 escravos na cidade de São Paulo, o que mostra que a maior parte dessa população encontrava-se no centro da cidade. Os dados demográficos auxiliam no entendimento de como a cidade cresceu e nos ajudam a entender o que se passou nas décadas seguintes.

São Paulo, como comentado anteriormente, torna-se um grande centro cultural e passa a ser visto diferentemente no país. Dois processos, assim, parecem operar nos falantes na cidade de São Paulo entre os anos de 1827 e 1872: um processo de urbanização (de que a instalação da Faculdade de Direito faz parte) e um processo de contato dialetal (impulsionado, entre outras razões, pelos migrantes que iam até a cidade de São Paulo por conta dos estudos, por exemplo). Hipoteticamente, a partir da instalação da faculdade em São Paulo, podemos dividir seus habitantes em três gerações:

1) 1827: Os paulistanos no momento da instalação da Faculdade de Direito;

2) 1850: Os filhos dos paulistanos que vivenciaram a instalação da faculdade e que, por conta disso, presenciam as mudanças socioeconômicas trazidas por esse evento;

3) 1872: dos 31.385 paulistanos, aproximadamente 11.000 são jovens de até 14 anos de idade. Estes indivíduos compõem essa geração. 
Lembramos que alguns anos mais adiante, em 1881, Ribeiro (1881) menciona a divisão entre os paulistanos e os "caipiras". Ou seja, a fala da terceira geração acima já apresentaria uma diferença clara entre esses dois grupos. Pensando em processos de mudança linguística por conta do contato dialetal, temos três estágios postos por Kerswill e Trudgill (2005, p. 200), baseados nas gerações dos indivíduos que habitam determinada região:

1) No primeiro estágio, ocorre um processo de nivelamento rudimentar, em que os migrantes adultos (primeira geração) encontram-se em situação de contato dialetal e uma forma variante passa a ganhar espaço em sua fala;

2) O segundo estágio está centrado na segunda geração de falantes: os filhos dos migrantes, que constituem a primeira leva de falantes nativos daquela variedade de fala. Aqui, ocorre grande variabilidade na fala dos indivíduos e o processo de nivelamento continua até a seleção de uma forma variante;

3) Por fim, no terceiro estágio, as gerações seguintes dão continuidade à formação do novo dialeto por meio de três processos: ainda há nivelamento das formas variantes, mas acompanhado da focalização (a estabilidade no uso de uma forma) e da realocação, em que há a atribuição de significado social às formas variantes.

A mudança dialetal ocorre nessa época e os períodos seguintes auxiliam no entendimento do prestígio atribuído a certos traços do dialeto paulistano.

\section{Os anos de 1870 a 1920}

Dourado (2005, p. 118) aponta que o número de paulistanos subiu de 65 mil habitantes para 230 mil na virada do século XIX para o XX. Em relação às atividades econômicas da época, de acordo com Matos (1955):

São Paulo era uma espécie de entreposto comercial, que mantinha contacto permanente com o pôrto de Santos e com a zona agrícola do interior, onde prosperava a lavoura canavieira e tinha início a expansão do café, no vale do Paraíba. Tais fatôres, embora modestos em suas proporções, bastavam para ocasionar uma certa animação à vida comercial da cidade (MATOS, 1955, p. 99).

A vida comercial paulistana se intensifica. A oposição “urbano vs. rural”, em 1872, é observada abaixo: 
Figura 1: área urbanizada da cidade de São Paulo em 1872

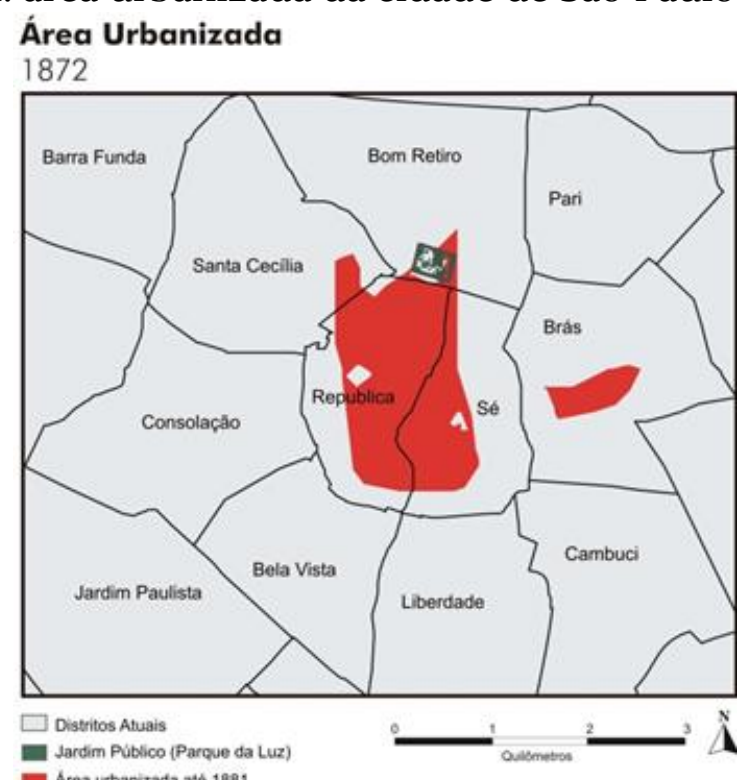

Fonte: Prefeitura de São Paulo (2018)

Ressaltamos que todos os bairros que compõem a figura acima dizem respeito, apenas, à região central da cidade de São Paulo. Pensar a área urbana é, também, refletir acerca de diferentes processos de desenvolvimento em termos de infraestrutura da cidade. Alguns exemplos ajudam a mostrar a malha urbana de São Paulo se desenvolvendo: em 1844, a Rodovia Caminho do Mar, com 35 quilômetros de extensão que ligava São Bernardo do Campo a Santos, foi inaugurada (BRISO, 2009). Já em 1870, houve o projeto do primeiro sistema de esgoto da cidade de São Paulo (SABESP, 2008), que só foi consolidado no ano de 1875 , dois anos antes dos primeiros debates sobre a criação do reservatório da Cantareira. Foi nessa época, também, que as primeiras ferrovias foram inauguradas, ligando São Paulo ao porto de Santos. Para as próximas quatro décadas, o quadro urbano se modifica:

Figura 2: área urbanizada da cidade de São Paulo em 1929 


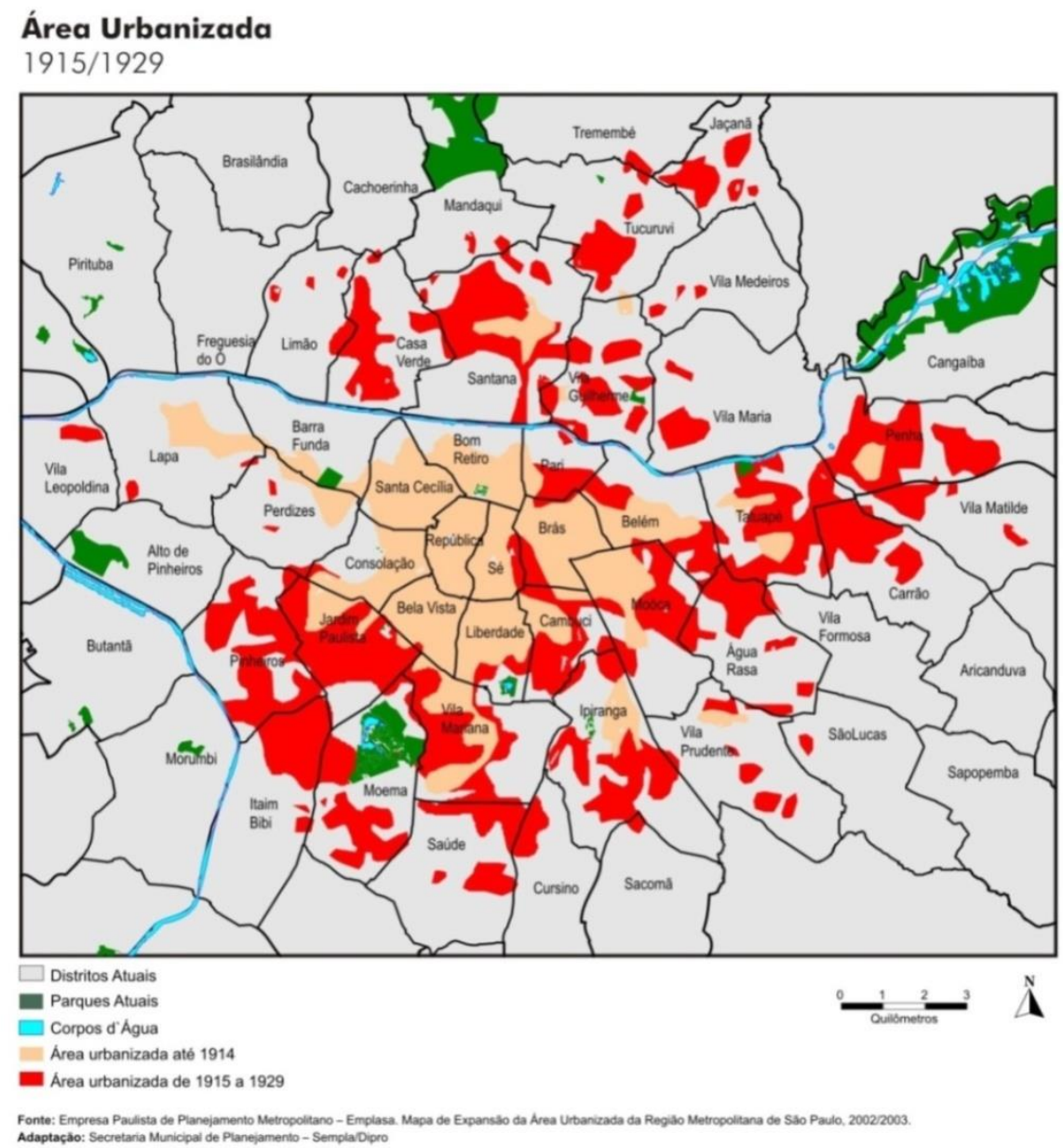

Fonte: Prefeitura de São Paulo (2018)

O espalhamento da infraestrutura fez com que a área urbana do município se expandisse, o que intensificou o marco entre a cidade e o campo, o urbano e o rural, na principal cidade do estado de São Paulo. Com base nos mapas acima, talvez consigamos delimitar os “caipiras de São Paulo", como posto por Ribeiro (1881), aos paulistanos que não moravam nos bairros centrais da cidade: Sé e República (conforme a Figura 1). Anos depois, a área urbana se expande e as zonas agrícolas passam a ser encontradas em pontos mais distantes do centro de São Paulo, de certa maneira “empurrados" pela urbanização. Isso faz com que, aos poucos, os “caipiras” sejam deslocados para o interior do estado, ou seja, longe da capital e de sua zona metropolitana. 


\section{Os anos de 1920 a 1970}

Em 1922, acontece a Semana de Arte moderna no Teatro Municipal de São Paulo - outro marco cultural, após a inauguração da Faculdade de Direito. De acordo com Dourado (2005, p. 118), em 1934, o município alcançaria a marca de um milhão de habitantes, subindo para dois milhões após 14 anos, em 1948, em que o êxodo do campo para a cidade ocorreu por conta da revolução industrial. Aqui, as divisões entre cidade e campo já estão bem definidas.

Dourado (2005, p. 117) ainda destaca que "as nove primeiras regiões metropolitanas do país surgiram em 1973", sendo uma delas a região metropolitana que engloba a cidade de São Paulo. O estado de São Paulo possui três regiões metropolitanas: a região metropolitana de São Paulo, criada em 1973 pela lei complementar Federal 17/73; a região metropolitana da Baixada Santista, criada em 1996 pela lei complementar Federal 815/96; e a região metropolitana de Campinas, criada em 2000 pela lei Complementar Estadual 870/200o. Dourado (2005, p. 119) ainda complementa esta informação apontando que

$$
\begin{aligned}
& \text { no que diz respeito, à área geográfica, as três regiões correspondem a 5,67\% da } \\
& \text { área do Estado de São Paulo e o,16\% da área do Brasil. Segundo o último censo } \\
& \text { [2004] a população que reside nessas três áreas corresponde a 58,6\% da } \\
& \text { população do Estado e 12\% da população do Brasil (DOURADO, 2005, p.119). }
\end{aligned}
$$

É interessante observar que a instrução para que traços paulistanos sejam inseridos na fala dos apresentadores de telejornais começa a ser defendida no ano de 1974, na mesma época em que São Paulo torna-se centro da região metropolitana do Sudeste. Nessa mesma época, há a inauguração de importantes rodovias no estado de São Paulo: ainda de acordo com Briso (2009), o trecho paulista da rodovia BR 101, que liga o estado do Rio Grande do Sul ao estado do Rio Grande do Norte, foi inaugurado em 1956 com 287 quilômetros de extensão. Outra rodovia importante, inaugurada em 1972, é a Rodovia Dom Pedro I, com 145 quilômetros de extensão. Por fim, a rodovia Raposo Tavares, com 25 quilômetros de extensão na região metropolitana de São Paulo, foi inaugurada em 1952. Essas rodovias servem, principalmente, àqueles que transitam na região metropolitana de São Paulo, o que auxiliou a região em sua caracterização como metrópole. Foi também, na metade do século XX, que as rodovias 
no litoral paulista foram inauguradas (DER, 2018), de forma a ligar todas as regiões do estado de São Paulo à sua capital de forma direta.

\section{Considerações finais}

O desenvolvimento paulista iniciou-se, de certa maneira, em um acontecimento relacionado à linguagem: a instalação da Faculdade de Direito, em 1827. Cabe nos perguntarmos se o desenvolvimento paulistano teria ocorrido no mesmo tempo e na mesma intensidade caso a faculdade não houvesse sido instalada em São Paulo. Teria a economia cafeeira por si só atraído, além dos olhares de diversos comerciantes, os artistas da Semana de Arte de 1922? Teriam as escolas de primeiras letras tido o mesmo prestígio que em outras cidades brasileiras? A marginalização dos ex-escravos, indígenas e africanos, da área urbana é fator de suma importância ao considerarmos o contato dialetal entre os paulistanos na primeira metade do século XIX. O que também leva à pergunta: teria a miscigenação paulista perdurado por mais tempo caso a expansão urbana tivesse tido forma e duração diferentes?

A primeira faculdade do Brasil foi a Escola de Cirurgia da Bahia, inaugurada em 1808, seguida pelas Faculdades de Direito de São Paulo e de Pernambuco. Salvador/BA, cidade da Escola de Cirurgia, foi a maior cidade brasileira do começo do século XIX, perdendo seu posto para o Rio de Janeiro apenas por conta da chegada do Príncipe Regente Dom João. As faculdades foram grandes impulsionadoras da urbanização para determinadas cidades. Com São Paulo, isso não foi diferente.

É importante ressaltar que, embora a implantação da Faculdade de Direito tenha sido um marco importante em termos linguísticos para a mudança na percepção do dialeto paulistano, esse fato por si só não é suficiente para essa alteração. Fatores sociais, por exemplo, têm mais peso do que o da implantação da faculdade em si. Em uma comparação, é possível pensar no caso da Faculdade de Direito de Pernambuco instalada no mesmo ano que a Faculdade de Direito de São Paulo - e na ausência de comentários sobre a pronúncia pernambucana nos debates da Constituinte de 1823. 
Os diferentes processos envolvidos na fundação das cidades ajudam a entender como determinada forma linguística pode ser vista com prestígio ou com estigma. Em especial, com a Faculdade de Direito de São Paulo, é possível observar uma instituição social que não apenas impulsiona a urbanização - e o desenvolvimento advindo dela mas que também recorta um espaço como centro de cultura e de civilidade, ao mesmo tempo em que delega a instrumentos normativos (como as gramáticas) a obrigação de que a língua dos sujeitos letrados expresse essas características.

\section{Referências}

AMARAL, A. O Dialecto Caipira. Editora O Livro: São Paulo, 1920.

BRASIL. Coleção das Leis do Império do Brasil - Decretos, Cartas Régias e Alvarás - 1823 (1887).

Disponível

em

<http://www.camara.gov.br/Internet/InfDoc/conteudo/colecoes/Legislacao/Páginas\% 2ode\%2oLegimp-F_45.pdf>. Acesso em: 28 abr. 2018.

. Coleção das Leis do Império do Brasil - Atos do Poder Legislativo - 1827 (1878).

Disponível

em

<http://www.camara.gov.br/Internet/InfDoc/conteudo/colecoes/Legislacao/LegimpJ.pdf>. Acesso em 28 abr. 2018.

BRISO, C. B. A história das estradas paulistas. Veja São Paulo, Cidades. 18 set. 2009. Disponível em: <https://vejasp.abril.com.br/cidades/a-historia-das-estradaspaulistas/>. Acesso em o9 mai. 2018.

BURTON, R. F. Explorations of the highlands in Brazil. Volume II. Londres: Tinsley Brothers, 1869.

CARNEIRO RIBEIRO, E. Serões Gramaticais. Bahia: Livraria Catilina, 1890.

COMPANHIA DE SANEAMENTO BÁSICO DO ESTADO DE SÃO PAULO (SABESP).

Dossiê: sistemas de Esgotamento Sanitário. São Paulo: Espaço das águas, 2008.

DER (DEPARTAMENTO DE ESTRADAS DE RODAGEM). Histórico de rodovias.

Disponível

em:

<http://www.der.sp.gov.br/Website/Acessos/Institucional/HistoricoRodovias.aspx>. Acesso em o9 mai. 2018. 
DOURADO, E. M. B. As Regiões Metropolitanas do Estado de São Paulo. Rev. adm. saúde; 7(29): 138-146, out.-dez. 2005.

GOMES, S. M. C. Gramáticas e o ensino das línguas no Brasil Império. História do Ensino de Línguas no Brasil, n. 4, 2010. Disponível em: <http://www.helb.org.br/index.php/revista-helb/ano-4-no-4-12010/140-gramaticase-o-ensino-das-linguas-do-brasil-imperio>. Acesso em 28 abr. 2018.

IBGE (INSTITUTO BRASILEIRO DE GEOGRAFIA E ESTATÍSTICA). Tabelas. Disponível em: <http://smul.prefeitura.sp.gov.br/historico_demografico/tabelas.php>. Acesso em 10 mai. 2018.

KERSWILL, P.; TRUDGILL, P. (2005) The birth of new dialects. In: AUER, P.; HINSKENS, F.; KERSWILL, P. (Eds.) Dialect change: convergence and divergence in European languages. Cambridge: Cambridge University Press, p. 196-220.

LABOV, W (1972). Sociolinguistic Patterns. Philadelphia: University of Pennsylvania Press. [Padrões Sociolinguísticos. Trad.: Marcos Bagno; Marta Scherre e Caroline Cardoso. São Paulo: Parábola, 2008.]

LAMBERT, W.E.; HODGSON, R. C.; GARDNER, R. C.; FILLENBAUM, S. Evaluational reactions to spoken language. Journal of Abnormal and Social Psychology, v. 6o, n.1, p. 44-51, 1960 .

MACIEL, M. de A. Grammatica descriptiva baseada nas doutrinas modernas. $3^{\underline{a}}$ ed. augmentada com muitas notas e resumos synopticos. Rio de Janeiro e Paris: H. Garnier Livreiro-Editor, 1902 [1894].

MARCÍliO, M. L. A cidade de São Paulo: povoamento e população (1750-1850). 1ª̣ed. São Paulo: Pioneira - EDUSP, 1974.

MATOS, O. N. A cidade de São Paulo no século XIX. Revista de história, n. 21-22, ano VI, São Paulo, jan./jul. 1955.

MAWE, J. Viagens ao interior do Brasil. ıªed. Belo Horizonte - São Paulo: Itatiaia Edusp, 1978.

MENDES, C. M. O falar do Jornal Nacional: produção e recepção de um sotaque de natureza ideológica. Monografia de graduação, Universidade Federal de Minas Gerais, 2006.

OUSHIRO, L. Identidade na pluralidade: avaliação, produção e percepção linguística na cidade de São Paulo. Tese doutorado. Universidade de São Paulo, Faculdade de 
filosofia, letras e ciências humanas, departamento de linguística. Programa de pósgraduação em semiótica e linguística geral. 2015.

POLACHINI, B. S; DANNA, S. M. D. G. Dados sintáticos do português brasileiro em gramáticas brasileiras oitocentistas. Estudos Linguísticos, 45 (1): p. 192-202, 2016.

PREFEITURA DE SÃO PAULO. Área Urbanizada 1872. Disponível em: <http://smul.prefeitura.sp.gov.br/historico_demografico/img/mapas/urb-1872.jpg>. Acesso em o1 mai. 2018.

PREFEITURA DE SÃO PAULO. Área Urbanizada 1915/1929. Disponível em: <http://smul.prefeitura.sp.gov.br/historico_demografico/1920.php>. Acesso em o1 mai. 2018.

RAMOS, J. M. Avaliação de dialetos brasileiros: o sotaque. Revista de Estudos da Linguagem. Belo Horizonte: UFMG. jan.-jun. 1997.

RIBEIRO, D. O Povo Brasileiro: A formação e o sentido de Brasil. (1 $\mathbf{1}^{\mathrm{a}}$ ed.). São Paulo: Companhia das Letras, 2006.

RIBEIRO, J. C. Grammatica Portugueza. São Paulo: Typographia de Jorge Seckler, 1881. ROBL, A. Influência tupi no português popular do Brasil. Letras, (34) 155-179, 1985. ROCHA, I. P. A Demografia Escrava em São Paulo em 1829: análise comparativa de estudos demográficos. Ciência et Praxis, v. 2, n.3, 2009.

RODRIGUES, A. N. O dialeto caipira na região de Piracicaba. São Paulo: Àtica, 1974.

SAID ALI, M. Gramática Histórica da Língua Portuguesa. São Paulo: Edições Melhoramentos, 1964 [1931].

SAINT-HILAIRE, A. M. Voyage dans les provinces de Saint-Paul et de Sainte-Catherine. Tome Premier. Paris: Arthus Bertrand, $1851 a$.

SAINT-HILAIRE, A. M. Voyage dans les provinces de Saint-Paul et de Sainte-Catherine. Tome Second. Paris: Arthus Bertrand, $1851 \mathrm{~b}$.

SIEGEL, J. Second Dialect Acquisition. Cambridge: Cambridge University Press, 2010. TOLEDO, R. P. A capital da solidão: Uma história de São Paulo das origens a 190o. São Paulo: Objetiva, 2012.

TRUDGILL, P. Dialects in Contact. New York: Basil-Blackwell, 1986.

\footnotetext{
* Mestre em Linguística pela Universidade Estadual de Campinas (UNICAMP). Atualmente, é doutorando em Linguística pela mesma instituição.
} 